\title{
Pengaruh Rasa Ingin Tahu Dan Percaya Diri Terhadap Kemampuan Literasi Sains Siswa Sekolah Menengah Atas Di Kota Tangerang Selatan
}

\author{
Tri Suwarno Handoko Noviyanto*, Sumaryoto, Suparman Ibrahim \\ Program Studi Magister Pendidikan MIPA, Fakultas Pascasarjana, Universitas Indraprasta PGRI, \\ Kota Jakarta Selatan, Jakarta, Indonesia \\ *Email: trisu.hn@gmail.com
}

\begin{abstract}
Abstrak
Tujuan penelitian ini untuk mengetahui: (1) pengaruh rasa ingin tahu dan percaya diri secara bersama-sama terhadap kemampuan literasi sains; (2) pengaruh rasa ingin tahu terhadap kemampuan literasi sains; dan (3) Pengaruh percaya diri terhadap kemampuan literasi sains. Metode yang digunakan adalah metode survey. Hasil penelitian ini menunjukkan bahwa: (1) terdapat pengaruh yang signifikan rasa ingin tahu dan percaya diri secara bersama-sama terhadap kemampuan literasi sains siswa SMA Negeri di Kota Tangerang Selatan. Hal ini dibuktikan dengan perolehan nilai Sig. $=0,045<0,05$ dan nilai $\mathrm{Fh}=3,210$; (2) terdapat pengaruh yang signifikan rasa ingin tahu terhadap kemampuan literasi sains siswa SMA Negeri di Kota Tangerang Selatan. Hal ini dibuktikan dengan perolehan nilai Sig. $=0,027<0,05$ dan nilai th $=2,252$; dan (3) terdapat pengaruh yang signifikan rasa percaya diri terhadap kemampuan literasi sains siswa SMA Negeri di Kota Tangerang Selatan. Hal ini dibuktikan dengan perolehan nilai Sig. $=0,048<0,05$ dan nilai th $=-2,010$. Dengan demikian dapat dibuktikan kemampuan literasi sains dapat dipengaruhi sikap rasa ingin tahu dan sikap percaya diri, baik secara parsial maupun bersama-sama.
\end{abstract}

Kata kunci: Literasi Sains, Percaya Diri, Rasa Ingin Tahu.

\section{Abstract}

The aim of this research is to know:(1) The influence of curiosity and self-confidence together to scientific literacy skills;(2) The influence of curiosity to scientific literacy skills;(3) The influence of self-confidence to scientific literacy skills. The method was used survey method. The results of this research indicate: (1) There is a significant influence of curiosity and self-confidence together to scientific literacy skills of State High Schools in South Tangerang City. This is evidenced by agreeing to the Sig. $=0.045<0.05$ and Fh= 3.210;(2) There is a significant influence of curiosity to scientific literacy skills of State High Schools in South Tangerang City. This is evidenced by agreeing to the Sig. $=0.027<0.05$ and th=2.252;(3) There is a significant influence of selfconfidence to scientific literacy skills of State High Schools in South Tangerang City. This is evidenced by agreeing to the Sig. $=0.048<0.05$ and th $=-2.010$. Thus it can be proven that scientific literacy skills can be influenced by curiosity and self-confidence, both partially and together.

Keywords: Scientific Literacy, Self-Confidence, Curiosity.

\section{PENDAHULUAN}

Capaian sains Indonesia dalam

Programme for International Student

Assessment (PISA) perlu terus ditingkatkan.

Peningkatan perlu terus diupayakan karena untuk saat ini hasil penilaian literasi sains Indonesia masih belum mencapai hasil yang baik. Merujuk pada hasil penilaian literasi sains Indonesia dalam kelipatan tiga tahun terakhir, memperlihatkan bahwa kemampuan literasi sains masih tergolong rendah. Hal tersebut dapat dijelaskan melalui Tabel 1.

Tabel 1. Data Literasi Sains Siswa Indonesia dalam Skala PISA

\begin{tabular}{cccc}
\cline { 2 - 4 } & \multicolumn{3}{c}{ TAHUN } \\
& $\mathbf{2 0 0 9}$ & $\mathbf{2 0 1 2}$ & $\mathbf{2 0 1 5}$ \\
\hline Skor Rata-rata PISA & 501 & 501 & 493 \\
Skor Rata-rata & 383 & 382 & 403 \\
Indonesia & & & 62 \\
Peringkat Indonesia & 60 & 64 & 62 \\
Negara Peserta PISA & 65 & 65 & 70 \\
\hline Sumber: OECD $(2009,2014,2016)$
\end{tabular}




\section{JPSP: Jurnal Penelitian Sains dan Pendidikan}

https://e-journal.iain-palangkaraya.ac.id/index.php/mipa/

Dari paparan tabel di atas, pencapaian siswa Indonesia di bidang sains memang memprihatinkan. Jika dibandingkan dengan rerata internasional, kemampuan literasi sains siswa Indonesia masih jauh di bawah rata-rata. Rendahnya rata-rata literasi sains siswa Indonesia pada PISA menjadi salah satu gambaran bahwa masih banyak pekerjaan rumah yang perlu diselesaikan untuk memperbaiki proses pembelajaran sains.

Perlunya siswa mempelajari sains bukan berarti untuk membuat siswa menjadi seorang saintis. Perlu dipahami bersama bahwa tujuan siswa mempelajari sains untuk membangun kemampuan literasi sainsnya. Arti kata bahwa siswa perlu memahami lebih dalam tentang apa dan kegunaan sains itu sendiri. Dalam proses pembelajaran sains, siswa tidak hanya diminta untuk sekedar menguasai pengetahuan konsep dan proses sains, akan tetapi siswa diarahkan untuk membuat suatu keputusan dan ikut berpartisipasi mengelola lingkungan berdasarkan pengetahuan sains yang ia miliki. Siswa yang pintar dalam sains, misalnya pelajaran biologi, belum tentu peka terhadap lingkungan sekitarnya. Siswa dengan kemampuan literasi sainsnya yang baik pasti tidak akan membuang sampah plastik secara sembarangan, tidak menghidupkan lampu di ruangan yang dijangkau cahaya matahari, atau tidak makan dan jajan sembarangan. Melihat kondisi nyata dalam keseharian kita, bahwa belum banyak siswa yang mengaplikasikan pengetahuan sainsnya dalam keseharian.

Hasil observasi peneliti ke beberapa SMA Negeri di Kota Tangerang Selatan, ditemukan bahwa bahasan sains, khususnya biologi cenderung menjadi pelajaran hapalan dibandingkan sebagai bekal pengetahuan untuk kehidupan sehari-hari. Padahal objek yang dipelajari pada bahasan biologi, perlu diketahui oleh siswa bagaimana proses atau kejadian dapat terjadi. Ketika siswa belajar untuk mencari tahu bagaimana peristiwa terjadi, maka secara tidak langsung akan menumbuhkan rasa ingin tahu pada diri siswa. Rasa ingin tahu menjadi modal awal untuk melangsungkan proses pembelajaran. Adanya rasa ingin tahu tentu akan mendorong siswa dalam memenuhi hasrat keingintahuannya. Rasa ingin tahu menjadi lebih mantap bila diiringi dengan rasa percaya diri. (Ningrum, 2019). Umumnya siswa yang percaya diri memiliki inisiatif dan sikap optimis dalam menjalani segala aktivitas (Dariyo, 2011). Percaya diri diibaratkan bagaimana seseorang berani berdiri di barisan paling depan, untuk mengatur serta menguasi situasi yang ada di sekitarnya. Itu artinya bahwa percaya diri dapat membuat siswa lebih mampu menjalankan proses belajar. Dengan bekal kepercayaan diri yang tinggi, maka rasa ingin tahu akan membawa siswa pada proses mencari dan menemukan pengetahuannya sendiri. Hal ini sejalan dengan konsep literasi sains, yakni siswa dapat memahami, mengkomunikasikan, serta mampu menerapkan konsep sains. Literasi sains secara etimologi, yakni literatus adalah melek huruf dan scientia adalah pengetahuan. PISA(Ali dkk., 2016) menjelaskan kemampuan literasi sains sebagai pengetahuan ilmiah pada seseorang, dan mendayagunakan pengetahuan tersebut untuk kegiatan mengidentifikasi pertanyaan, memperoleh pengetahuan, menjelaskan 


\section{JPSP: Jurnal Penelitian Sains dan Pendidikan}

https://e-journal.iain-palangkaraya.ac.id/index.php/mipa/

fenomena ilmiah, dan menguraikan peristiwa sains dengan menggunakan hukum, prinsip, dan konsep ilmiah. Seseorang dengan literasi sainsnya akan memahami karakteristik utama sains sebagai bentuk pengetahuan dan investigasi ilmiah.

Kurniasih \& Sani (2017) menjelaskan rasa ingin tahu sebagai suatu sikap dan perbuatan yang ditujukan untuk mengetahui secara lebih detail dari apa yang sedang dilihat, didengar dan dirasakan. Sari (2016) memaparkan rasa ingin tahu sebagai suatu perbuatan untuk mengetahui dan mencari informasi terhadap suatu hal yang belum diketahui. Rasa ingin tahu menjadi modal awal siswa dalam menjalani proses pembelajaran. Keingintahuan yang besar menyebabkan siswa ingin memenuhi hasrat keingintahuannya akan pengetahuan yang sedang didalami. Mencari tahu hal yang belum diketahui akan memunculkan minat siswa untuk belajar lebih giat. Sikap demikian merupakan sikap seorang saintis, yang mengarahkan siswa untuk terus belajar dalam memahami pengetahuan secara lebih dalam.

Percaya diri merupakan sikap positif untuk menumbuhkan penilaian positif, baik terhadap diri sendiri maupun terhadap situasi yang tengah dihadapi. Hal ini bukan juga diartikan bahwa seseorang dengan kepercayaan dirinya dianggap sebagai pribadi yang sakti (Hulukati, 2016). Percaya diri tentunya memegang peranan penting bagi keberhasilan seseorang dalam hidupnya. Berbeda dengan seseorang yang tidak percaya diri, tentunya setiap langkah dan tindakan yang dilakukan akan terhambat karena sikap ketidakpercayaan diri yang ditumbuhkannya sendiri.

Berdasarkan latar belakang tersebut, penelitian dilakukan dengan tujuan, antara lain: (1) mengetahui pengaruh rasa ingin tahu dan percaya diri secara bersama-sama terhadap kemampuan literasi sains siswa SMA Negeri di Kota Tangerang Selatan; (2) mengetahui pengaruh rasa ingin tahu terhadap kemampuan literasi sains siswa SMA Negeri di Kota Tangerang Selatan; dan (3) mengetahui pengaruh rasa percaya diri terhadap kemampuan literasi sains siswa SMA Negeri di Kota Tangerang Selatan.

\section{METODE PENELITIAN}

Waktu penelitian dilaksanakan selama 2 (dua) bulan, terhitung mulai bulan Oktober sampai dengan November 2018, pada Semester Ganjil Tahun Akademik 2018/2019. Penelitian ini dilaksanakan di SMAN 1 Kota Tangerang Selatan, SMAN 4 Kota Tangerang Selatan, dan SMAN 8 Kota Tangerang Selatan. Pemilihan tempat penelitian didasarkan atas kesesuaian antara tujuan dan jangkauan daerah penelitian.

Penelitian ini menggunakan metode survey, yakni metode penelitian yang datanya diperoleh dari suatu tempat tanpa perlu memberikan perlakuan. Fokus penelitian ini untuk mencari pengaruh dari dua variabel bebas terhadap variabel terikat, dan masingmasing dari variabel bebas terhadap variabel terikat. Adapun desain konstelasi dari penelitian pengaruh rasa ingin tahu dan percaya diri terhadap kemampuan literasi sains dapat dilihat pada Gambar 1. 
https://e-journal.iain-palangkaraya.ac.id/index.php/mipa/

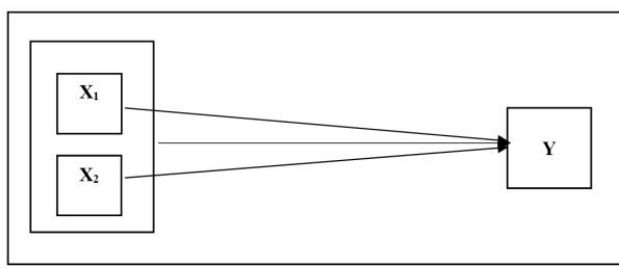

Keterangan :

$\mathrm{X}_{1}$ : Rasa Ingin Tahu

$\mathrm{X}_{2}$ : Percaya Diri

$\mathrm{Y}:$ Kemampuan Literasi Sains

Gambar 1. Model Konstelasi Hubungan antar Variabel Penelitian

Populasi dalam penelitian ini adalah siswa kelas $\mathrm{X}$ Jurusan IPA di tiga Sekolah Menengah Atas Negeri di Kota Tangerang Selatan yang berjumlah 567 siswa. Melalui penghitungan Taro Yamane sebagaimana rumus berikut, diperoleh data sampel sebesar 85 siswa.

$$
n=\frac{N}{N d^{2}+1}
$$

Keterangan :

$\begin{array}{lll}\mathrm{n} & \text { : Ukuran sampel } \\ \mathrm{N} & \text { : Ukuran populasi } \\ \mathrm{d} & \text { : Tingkat kesalahan pengambilan } \\ \text { sampel } & \text { yang dapat ditolerir }\end{array}$

Adapun untuk menentukkan banyaknya anggota sampel dari masing-masing sekolah, digunakan teknik proporsional sebagai berikut:

$$
n_{i}=\frac{N_{i}}{N} \times n
$$

\section{Keterangan :}

$n_{i} \quad$ : Sampel masing-masing sekolah

$N \quad$ : Total populasi

$N_{i} \quad$ : Populasi masing-masing sekolah

$n \quad$ : Total sampel
Dengan demikian, dari penghitungan yang dilakukan, maka perwakilan dari masingmasing sekolah dapat dilihat pada Tabel 2.

Tabel 2. Data Literasi Sains Siswa Indonesia dalam Skala

\begin{tabular}{lcc}
\hline \multicolumn{1}{c}{ Sekolah } & $\begin{array}{l}\text { Populasi } \\
\text { Sekolah }\end{array}$ & $\begin{array}{c}\text { Anggota } \\
\text { Sampel }\end{array}$ \\
\hline $\begin{array}{l}\text { SMAN 1 Kota } \\
\text { Tangsel }\end{array}$ & 214 siswa & 32 siswa \\
$\begin{array}{l}\text { SMAN 4 Kota } \\
\text { Tangsel }\end{array}$ & 174 siswa & 26 siswa \\
$\begin{array}{l}\text { SMAN 8 Kota } \\
\text { Tangsel }\end{array}$ & 179 siswa & 27 siswa \\
Total & 567 siswa & 85 siswa \\
\hline
\end{tabular}

Alat ukur rasa ingin tahu dengan menggunakan angket, yang mana indikator instrumen diadopsi dari Berlyne (Rowson, 2012), yakni: (1) epistemic curiosity, keingintahuan untuk memperoleh informasi; (2) perceptual curiosity, keingintahuan untuk mengakomodasi pengalaman melalui indra; (3) specific curiosity, keingintahuan untuk mengenal lebih dalam bagian dari pengetahuan yang ada; dan (4) diversity curiosity, keingintahuan untuk mengeksplorasi pengetahuan atau informasi. Alat ukur percaya diri dengan menggunakan angket, yang mana indikator instrumen diadopsi dari Lauster (Rahayuningdyah, 2016), yakni: (1) keyakinan pada kemampuan diri sendiri; (2) memiliki sikap optimis; (3) bertindak objektif; (4) bertanggung jawab; dan (5) rasionalitas dan realistis. Adapun alat ukur kemampuan literasi sains dengan menggunakan soal tes pilihan ganda khusus pada artikel berkaitan dengan wacana biologi. Indikator instrumen mengacu pada Dimensi Literasi Sains PISA 2015 dengan dimensi kompetensi sebagai unit indikator 
https://e-journal.iain-palangkaraya.ac.id/index.php/mipa/

utama, yang didukung dimensi pengetahuan,

konteks, dan level kognitif (OECD, 2015).

Tabel 3. Dimensi Literasi Sains PISA 2015

\begin{tabular}{llll}
\hline & \multicolumn{2}{c}{ Dimensi } \\
Kompetensi & Pengetahuan & Konteks & $\begin{array}{c}\text { Level } \\
\text { Kognitif }\end{array}$ \\
\hline Menjelaskan & Konten-kehidupan & Personal- & Rendah \\
fenomena & Konten-bumi & kesehatan & Sedang \\
secara ilmiah & Konten-fisik & Lokal-sumber & Tinggi \\
Mengevaluasi & Prosedural & daya alam & \\
dan mendesain & Epistemik & Lokal/ & \\
percobaan & & nasional- & \\
ilmiah & & kualitas & \\
Menginterpret & & lingkungan & \\
asikan data & & Lokal/ & \\
dan fakta & & nasional- & \\
secara ilmiah & & bencana & \\
& & Global-frontier & \\
& & &
\end{tabular}

Contoh perincian indikator dimensi literasi sains pada butir tes pada Tabel 4.

Tabel 4. Butir Tes Literasi Sains

\begin{tabular}{|c|c|c|c|}
\hline \multirow{4}{*}{ 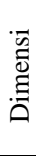 } & Kompetensi & • & $\begin{array}{l}\text { Menjelaskan fenomena } \\
\text { secara ilmiah }\end{array}$ \\
\hline & Pengetahuan & : & Konten - kehidupan \\
\hline & Konteks & : & Lokal/nasional - bencana \\
\hline & Level Kognitif & $:$ & Sedang \\
\hline
\end{tabular}

Serangan ulat bulu yang pernah terjadi di Tanjung Duren Utara, Jakarta Barat, adalah akibat dari perubahan cuaca ekstrim yang terjadi di Ibu Kota. Hampir 1.800 ulat bulu berkembang di sekitar 30 pohon cemara milik Suku Dinas Pertamanan. Agar tidak berkembang lebih besar lagi, warga pun melakukan pembasmian dengan cara membakar ulat-ulat tersebut. Cara ini dianggap efektif guna menangkal serangan ulat-ulat tersebut.

(Sumber: Kompas.com)

Berdasarkan artikel tersebut, alasan yang tepat untuk menjelaskan mengapa ulat bulu berkembang lebih cepat adalah .... .

a. warga banyak memburu burung pemakan ulat

b. banyaknya daun-daun sebagai makanan konsumsi ulat

c. ibu kota menjadi tempat yang cocok untuk habitat ulat

d. cuaca memicu siklus hidup ulat menjadi lebih pendek

e. perkembanganbiakan ulat karena tidak adanya hujan di ibu kota

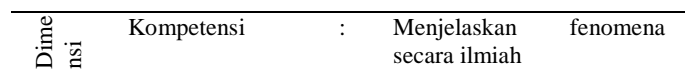

\begin{tabular}{lcl} 
Pengetahuan & $:$ & $\begin{array}{l}\text { Konten }- \text { bumi } \\
\text { Lokal/nasional } \\
\text { Konteks }\end{array}$ \\
Level Kognitif $\quad:$ & Sedangan \\
\hline Mangrove di Desa Lalombi
\end{tabular}

Desa Lalombi merupakan salah satu desa di Kecamatan Banawa Selatan yang sebagian besar wilayahnya berupa mangrove. Akan tetapi, selama empat tahun terakhir kondisi luas hutan mangrove di Desa Lalombi mengalami penurunan luas sekitar $57,74 \%$. Hasil analisis perubahan penggunaan lahan yang dilakukan melalui citra satelit menunjukkan bahwa luas semula $71 \mathrm{Ha}$ berkurang menjadi $30 \mathrm{Ha}$, dengan kondisi tidak lagi membentuk kawasan hutan mangrove secara utuh. Kerusakan hutan mangrove terjadi akibat aktivitas penduduk setempat seperti konversi untuk tambak, serta pertanian kebun kelapa dan kelapa sawit.

(Sumber: Jurnal GeoTadulako, Vol. 3 No. 6, 2015.)

Berdasarkan artikel tersebut, sebuah langkah yang bisa dilakukan untuk meningkatkan produktivitas Desa Lalombi serta mengembalikan kondisi seperti semula ialah ...

a. melakukan sosialisasi pentingnya hutan mangrove

b. memberdayakan warga dalam mengelola lingkungan dengan baik

c. menanam kembali hutan mangrove yang telah rusak untuk dijadikan tempat budidaya perikanan

d. memberi sanksi tegas kepada para warga yang melakukan pengrusakan mangrove

e. menjadikan Desa Lalombi sebagai objek wisata mangrove

Penelitian ini menggunakan langkah analisis data penelitian survey dengan regresi ganda yang dibantu dengan aplikasi SPSS. Untuk melaksanakan setiap tahap uji hipotesis, sebelumnya dilakukan pengujian deskripsi data dan uji persyaratan analisis data, berupa multikolinearitas, heteroskedastisitas, normalitas data, normalitas galat, dan linearitas. Setelah keseluruhan uji persyaratan analisis data dapat dipenuhi dan diketahui bahwa data layak untuk diolah lebih lanjut. Pengujian hipotesis selanjutnya untuk mendapatkan data anova signifikansi dari kedua variabel bebas terhadap variabel terikat, dan uji signifikansi secara parsial. 


\section{JPSP: Jurnal Penelitian Sains dan Pendidikan}

https://e-journal.iain-palangkaraya.ac.id/index.php/mipa/

\section{HASIL PENELITIAN}

Data hasil uji hipotesis dijelaskan melalui data Anova, data koefisien regresi dan uji signifikansi parsial pada Tabel 5 dan Tabel 6.

Tabel 5. Data ANOVA dengan Signifikansi Pengaruh Variabel Bebas secara Bersama-sama Terhadap Variabel Terikat

\begin{tabular}{cc}
\hline $\mathbf{F}$ & Sig. \\
\hline 3.210 & $.045 \mathrm{~b}$ \\
\hline
\end{tabular}

Tabel 6. Data Koefisien Regresi dan Uji Signifikansi secara Parsial

\begin{tabular}{ccc}
\hline Variabel & T & Sig. \\
\hline Rasa Ingin Tahu & 2.252 & .027 \\
Percaya Diri & -2.010 & .048 \\
\hline
\end{tabular}

Berdasarkan Tabel 5 dan Tabel 6, masalah dapat terjawab. Tabel 5 menunjukkan

\section{PEMBAHASAN}

Rasa ingin tahu menjadi prasyarat motivasi untuk dapat melakukan eksplorasi dalam menjalankan aktivitas belajar, terutama dalam mengasah kemampuan literasi sains. Dengan mengembangkan sikap rasa ingin tahu maka akan merangsang siswa untuk berkeinginan dalam mendalami pengetahuan, terutama dalam bidang sains. Rasa ingin tahu menjadi sebuah karakter yang dapat mempengaruhi kemampuan literasi sains. Seperti juga yang dipaparkan Suyanto (Temuningsih et al., 2017; Veronicatama et al., 2016) bahwa rasa ingin tahu memicu semangat mendalami pengetahuan, sehingga tidak dapat dipungkiri bahwa kemampuan literasi sains bahwa terdapat pengaruh yang signifikan rasa ingin tahu dan percaya diri secara bersamasama terhadap kemampuan literasi sains siswa SMA Negeri di Kota Tangerang Selatan. Hal ini dibuktikan dengan perolehan nilai Sig. = $0,045<0,05$ dan nilai Fhitung $=3,210$.

Tabel 6 menunjukkan bahwa terdapat pengaruh yang signifikan rasa ingin tahu terhadap kemampuan literasi sains siswa SMA Negeri di Kota Tangerang Selatan. Hal ini dibuktikan dengan perolehan nilai Sig. $=0,027$ $<0,05$ dan nilai thitung $=2,252$. Tabel 4 juga menjelaskan bahwa terdapat pengaruh yang signifikan rasa percaya diri terhadap kemampuan literasi sains siswa SMA Negeri di Kota Tangerang Selatan. Hal ini dibuktikan dengan perolehan nilai Sig. $=0,048<0,05$ dan nilai thitung $=-2,010$.

siswa akan berkembang seiring dengan berjalannya waktu.

Dalam proses belajar, rasa ingin tahu harus terus dipupuk dan dikembangkan agar dapat menjadi jembatan bagi siswa untuk memperoleh pengetahuan. Selain pengetahuan, terdapat ranah psikomotorik dan juga ranah sikap yang dapat dikembangkan dengan adanya sikap ini. Rasa keingintahuan yang besar tentu saja akan menyebabkan siswa ingin memenuhi hasrat keingintahuannya akan pengetahuan yang sedang didalami. Mencari tahu hal yang belum diketahui akan memunculkan minat siswa untuk belajar lebih giat.

Dari data yang diperoleh bahwa percaya diri juga menentukan kemampuan 
https://e-journal.iain-palangkaraya.ac.id/index.php/mipa/

literasi sains. Siswa hanya perlu selalu diarahkan untuk percaya diri dalam setiap aktivitas pembelajaran, seperti berani bertanya, berani mengemukakan argumen, bertanggung jawab terhadap tugas yang diberikan, dan lain sebagainya. Sebagaimana Pannen (Pratiwi \& Laksmiwati, 2016) dikatakan bahwa percaya diri menjadi faktor penting dalam pencapaian kemandirian belajar pada siswa. Seorang siswa dengan kepercayaan dirinya tentu akan mudah dalam mengambil keputusan, yang mana hal tersebut dapat membantu siswa dalam mengaplikasikan kemampuan literasi sainsnya. Berkan dan Ekici (R. Ahmad Zaky El, 2015) dijelaskan bahwa percaya diri memiliki peran yang signifikan terhadap pemahaman konsep yang baik, yang mana siswa dapat menggunakan konsep dan proses dari apa yang dipelajari dalam kesehariannya.

Dalam aktivitas pembelajaran, rasa ingin tahu yang disertai dengan percaya diri dapat membuat siswa untuk mencari dan menemukan pengetahuannya secara mandiri. Hal ini senada dengan konsep literasi sains, dimana siswa mampu untuk memahami, mengkomunikasikan, serta dapat menerapkan konsep sains dalam kehidupan nyata.

\section{SIMPULAN}

Berdasarkan pembahasan, peneliti menyimpulkan bahwa: (1) Ada pengaruh yang signifikan rasa ingin tahu dan percaya diri secara bersama-sama terhadap kemampuan literasi sains siswa SMA Negeri di Kota Tangerang Selatan; (2) Ada pengaruh yang signifikan rasa ingin tahu terhadap kemampuan literasi sains siswa SMA Negeri di Kota Tangerang Selatan.; (3) Ada pengaruh yang signifikan rasa percaya diri terhadap kemampuan literasi sains siswa SMA Negeri di Kota Tangerang Selatan.

Peneliti merekomendasikan para guru sains agar dapat membantu siswa menumbuhkembangkan kemampuan literasi sainsnya, sehingga apa yang telah dipelajari oleh siswa dapat diaplikasikan dalam kehidupan sehari-hari. Selain itu diharapkan para guru sains mengembangkan kreativitas dalam mengajar sehingga hal tersebut dapat membantu siswa dalam mengembangkan rasa ingin tahu dan percaya diri dalam kegiatan belajar mengajar.

\section{DAFTAR PUSTAKA}

Ali, A., Ardiansyah, I., Irwandi, D., \& Murniati, D. 2016. Analisis Literasi Sains Siswa Kelas XI Ipa Pada Materi Hukum Dasar Kimia Di Jakarta Selatan. Jurnal Kimia Dan Pendidikan, 1(2): 149-161.

Pratiwi ID \& Laksmiwati, H. 2016. Kepercayaan Diri dan Kemandirian Belajar Pada Siswa SMA Negeri "X." Jurnal Psikologi Teori Dan Terapan, 7(1), 43-53.

Zaky AR. 2015. 176944-ID-hubungan-literasisains-dan-kepercayaan.

Jurnal Penelitian Dan Pembelajaran IPA, 1(1), $16-25$.

Temuningsih, T., Peniati, E., \& Marianti, A. 2017. Pengaruh Penerapan Model Problem Based Learning Berpendekatan Etnosains Pada Materi Sistem 


\section{JPSP: Jurnal Penelitian Sains dan Pendidikan}

https://e-journal.iain-palangkaraya.ac.id/index.php/mipa/

Reproduksi Terhadap Kemampuan

Berpikir Kritis Siswa. Journal of

Biology Education, 6(1): 70-79.

Veronicatama, R. R. A., Ramli, M., Sari, D. P., \& Astorini, S. 2016. Penerapan Model Pembelajaran Inkuiri Untuk Meningkatkan Rasa Ingin Tahu Siswa Pada Materi Sistem Reproduksi Kelas Xi Mia 8 Sma Negeri 1 Karanganyar Tahun Pelajaran 2014/2015. BioPedagogi, 5(2): 26-35
Dariyo, A. 2011. Psikologi Perkembangan Anak Tiga Tahun Pertama. Bandung: Refika Aditama.

Hulukati, W. 2016. Pengembangan Diri Siswa SMA. Gorontalo: Ideas Publishing.

Kurniasih, I. \& Sani, B. 2017. Pendidikan Karakter Internalisasi dan Metode Pembelajaran di Sekolah. Jakarta: Kata Pena.

OECD. 2015. PISA 2015 Released Field Trial Cognitive Items.

Rowson, J. 2012. The Power of Curiosity. England: RSA Social Brain Centre. 